\title{
Reflections on the use of oral history techniques in social research
}

\author{
Elaine Batty* \\ Sheffield Hallam University
}

\begin{abstract}
Summary
This article draws on the author's experience of undertaking an oral history of her mother, as part of a Masters Degree. The paper endorses oral histories as a valid methodology and challenges some of the criticisms raised, specifically regarding memory and interview relationships. Traditionally, the written word has provided the favoured medium for capturing historical events, but the data must be questioned to establish if they are genuine or not; who was the author, for what social purpose were they produced. Thus they may paint a biased picture of the past. The voice of 'ordinary people' has been ignored and therefore their experiences have remained obscured. Critics such as Hobsbawm (1997) are quick to highlight the limitations of oral histories and suggest that oral histories rely heavily on memory, which can be flawed and prone to exaggeration. I contest Hobsbawm's (1997) assertions that memory is necessarily flawed; my mother's memory was acute and extremely detailed; the data generated were rich. Interview relationships are also questioned, suggesting that the more intimate the relationship between interview and interviewer, the more the desire for social conformity is increased. In the light of my experience, there is no evidence to suggest that my intimate relationship with my mother influenced the research process.
\end{abstract}

Key words: oral history, interviewing, memory, social research.

\section{Introduction}

This article draws on the author's experience of undertaking an oral history as part of a Masters Degree. The aim of the research was to capture my mother's experiences throughout her childhood in Sheffield in the 1930s and 40s. The paper does not present any of the contents of the interviews, which are personal, but rather it aims to reflect on some of the methodological issues involved in undertaking an oral history. Memory forms the central tenet of debates about the validity of oral histories as a research technique and this poses an interesting dichotomy: without memory oral histories would not exist; conversely, the reliability of memory is questionable. Inextricably linked to these issues, is the influence of relationships of power and trust within the interview situation. My use of an oral history technique was influenced by 
these factors and this article explores some of these issues and discusses them in the light of my own experience.

The article argues that oral histories are a valid form of research and can transcend its limitations to become an important method of social research. There is a time and place for oral histories in social research but like all methodologies they have to be used appropriately to ensure reliable and valid data.

\section{The use of oral histories in research}

The modern concept of oral history or biographical research was developed in the 1940s by Nevins (1996) and was particularly embraced in the 1960s and 1970s when inexpensive methods became available to document such rising social movements as civil rights, feminism, and anti-Vietnam War protests. The role of biographical research is to provide a diverse methodological and interpretative way to enable individual accounts of life experiences to be understood within contemporary cultural and structural settings. It can help researchers to understand major social shifts, by examining how new experiences are interpreted by individuals and families. Its philosophical and theoretical approach encompass qualitative techniques which enable the researcher to get close to the experiences and the views of the researched about how things are and why; representing a clear shift away from positivist empiricism (Roberts, 2002; Ritchie and Lewis, 2003).

Letting research participants tell their own story directly rather than having their lives written about by a distant outsider is the basic tenet of oral history approaches, which involve intensive and extended data collection comprising several interviews with each participant where they are given free rein to shape their own narratives (Ritchie and Lewis, 2003). Proponents of the use of oral histories such as Thompson (2000), Bryman (1998) and Roberts (2002) focus on their ability to view events from a participant perspective and to capture the changing experiences and outlooks of participants in their daily lives. Importantly, these perceptions can inject a more democratic view into the myopic vision of existing records as witnesses from the lower classes, the underprivileged and the defeated can be given a voice, facilitating a more realistic and fair reconstruction of the past.

by introducing new evidence from the underside, by shifting the focus and opening new areas of inquiry, by challenging some of the assumptions and accepted judgements of historians, by bringing recognition to substantial groups of people who had been ignored, a cumulative process of transformation is set in motion (Thompson, 2000:8).

Portelli (1981) suggests that oral history approaches are not merely interested in 'facts' but in the participant's perception of what is true (Portelli, 1981 cited in Roberts 2002: 105). In other words, biographical research begins with an empty void and shuns the formulation of theories and concepts prior to the research. Bryman summarises this as:

viewing events, actions, norms, values etc from the perspective of the people who are being studied; to provide detailed descriptions of the social settings; commitment to understanding events, behaviour etc in their context; a research strategy which is relatively open and unstructured; the rejection of the formulation of theories and concepts in advance of field work which may impose a potentially alien framework on subjects. (Bryman, 1998: 61). 
Roberts (2002) also emphasises the role of the individual and the freedom biographical research gives individuals to express themselves:

Biographical research seeks to understand the changing experiences and outlooks of individuals in their daily lives, what they see as important, and how to provide interpretations of the accounts they give of their past, present and future (Roberts, 2002: 1).

These commentators concur that the lived experience can be understood through the stories people tell. In this telling, we remember, we rework and re-imagine and reflect back on the past (Berger et al., 2005).

Intrinsically linked to the participant's perspective is memory, without which oral histories would not exist. However, the main criticisms of oral histories are aimed at the actual reliability of memory and the societal factors that influence and manipulate perceived memory. In addition, because oral histories are inherently unique to each individual, their generalisability and power to understand wider social developments is also questioned. Hobsbawn (1997) questions how far the recollections of one person can be generalised and suggests that one person is not representative beyond anyone other than themselves. The dominant tendency in oral history has been to use written factual evidence rather than the potentially more insightful testimonies of verbally articulated personal experiences. Despite the potential of oral histories to give a voice to marginalised groups, they do not neatly follow Marwick's (1970)1 acceptable traditional hierarchy of sources and Hobsbawm (1997) suggests that an oral history approach is unreliable compared with documentary evidence on the grounds that interviewees misremember events and exaggerate:

Most oral history today is personal memory which is a remarkably slippery medium for preserving facts (Hobsbawm, 1997: 206).

Thompson (2000) has argued that the memory process depends not only on individual comprehension but also upon an individuals' personal interest in particular subjects. Memory is therefore much more accurate when it matches an individual's social interest and need. Reliability depends partly therefore on whether the question or the subject interests the informant.

Critics have also raised questions about the reliability and validity of oral histories with particular reference to the inconsistency of memory, especially where interviews are conducted years after the events being recounted (Hoffman, 1996 cited in Roberts, 2002: 105). Cutler in particular has raised serious doubts about memory and the effects of the wider cultural milieu and other influences on the validity of oral testimony (Cutler, 1970 cited in Perks et al., 1998: 39). Summerfield (2004) also challenges the distinctions made between discourse and experience as articulated through language:

Historians who claim that accounts of lived experience give access to social reality, falsely separate discourse and experience: experience cannot exist outside discourse, agency cannot exist independently of language (Summerfield, 2004: 67).

Memories recalled are made sense of and interpreted by language and concepts known to the person remembering and these are influenced in turn by the wider social and cultural environment within which an individual is situated: The challenge therefore is for the researcher to understand the "cultural ingredients" that make up the remembered and interpreted past. Understanding the narrative within context is an important feature of oral history (Summerfield, 2004: 67). 
Oral histories are therefore understood to be a mechanism for helping us to understand the cultural milieu in which individual events were experienced, rather than a means of capturing the 'general experiences' of a population.

\section{Oral histories and interview relationships}

Oral histories are usually captured through the use of an interview process. The strengths of interview relationships are embedded within the qualitative research paradigm. The act of qualitative interviewing in itself denotes an interview/interviewee relationship; and ideally one that fosters trust. This is significant in the case of oral histories, where recounting personal experiences can be extremely fulfilling and cathartic, but conversely in some instances, traumatising. The philosophical and theoretical approach of qualitative research allows it to get close to the experiences and views of the researched through in-depth exploration capturing how individuals construct meaning and explore their own perceptions:

Qualitative researchers are concerned with the individual's point of view ... investigators think they can get closer to the actor's perspective through detailed interviewing and observation (Denzin and Lincoln, 2000: 10).

Qualitative researchers stress the socially constructed nature of reality, the intimate relationship between the researcher and what is studied, and the situational constraints that shape enquiry. They seek answers to questions that stress how social experience is created and given meaning (Denzin and Lincoln, 2000: 8).

Bryman (1988: 8) usefully summarises these emphases within qualitative interview techniques as 'the way in which people being studied understand and interpret their social reality' (Bryman, 1988: 8).

In-depth interviews combine structure with flexibility and are underpinned by a thematic approach enabling spontaneous responses to be fully explored. An interviewee's initial response is regarded as usually being at a surface level: the interviewer will subsequently use follow up questions to obtain a deeper and fuller understanding of the participant's meaning, reasons, feelings, opinions and beliefs (Ritchie and Lewis, 2003; Douglass and Moustakas, 1995; Olesen, 2000; Oakley, 1981).

Postmodern research approaches emphasise the way in which a reality is constructed in the interview, and the relationship that develops between researcher and respondent. Creative interviewing emphasises the importance of free expression whilst heuristic approaches stress the centrality of the personal experience of the interviewer, for instance proponents of feminist interviewing methods argue for the need for the process to be more reflective and interactive (Olesen, 2000; Oakley, 1981). This emphasis on depth, nuance and the interviewee's own language as a way of understanding meaning implies the need for face to face interviewing which can be an intense experience and may enable both parties to gain interactive and generative meaning (Ritchie and Lewis, 2003).

However, the reliability of memory is again questioned within the interview method used and Hobsbawm (1997) suggests that the interviewer dimension may actually perpetuate flaws in a participant's memory. Ritchie and Lewis (2003) believe that people are affected by the process of being studied and that the relationship between 
the researcher and social phenomena is interactive, thus undermining objectivity. Findings are either mediated through the researcher (value mediated) or negotiated and agreed with the participants. A valid concept somewhere between these two positions is that of empathic neutrality; a position that recognises that research cannot be value free but which advocates that researchers should make their assumptions transparent (Ritchie and Lewis, 2003). This acknowledges that the interviewer always has a social presence, even when attempting not to reveal any spoken opinions which could influence the participant. If the social relationship in an interview becomes, or is from the start, a social bond, the danger towards social conformity in participant's replies is increased. Conversely, there are no guarantees that increased intimacy will bring less inhibition on the part of the interviewee (Thompson, 2000; Hobsbawm, 1997).

Interview relationships can be problematic and the balance of power between the interviewer and participant, detachment and objectivity can be influential. In the process of interview and analysis, researchers may presume to understand the consciousness of the participant. However, researchers may bring to bear their own philosophical beliefs, which may be in direct contradiction to the participant. If the interpretation of the researcher and the participant diverge, in a life history, the researcher's interpretation would be more likely to take precedence (Thompson, 1994). In the case study discussed in this article, my being a close relative did not appear to inhibit my mother from discussing certain aspects of the past. Rather, she appeared quite willing to talk openly and candidly about her experiences, ensuring that the interviews were robust.

Qualitative researchers also face a series of important ethical issues. Mason (1996) discusses ways in which these ethical issues impinge on the qualitative researcher because the detailed character of qualitative research can mean intimate engagement with the public and private lives of individuals and Thompson (1994) concurs with Mason (1996) and states that:

Interviews which explore the ways in which a person has remembered his or her past can be rewarding for the interviewer but may be disturbing or even damaging for the interviewee. Unlike the therapist, oral historians may not be around to put together the pieces of memories that have deconstructed and are no longer safe (Thompson et al., 1994: 34 cited in Roberts, 2002: 104).

The issues discussed above are particularly relevant in the case of oral histories as the researcher is engaged in something much more intimate than is usual in a more formal or restricted interview. Oral histories are a window into a person's life and can on occasion unearth memories and issues that have been buried or forgotten for a number of years, which can have potential negative effects on the participants. The very nature of oral history approaches means that unexpected memories can surface, introducing new and challenging ethical dilemmas during the course of the research.

The questions raised here about interviewing techniques to draw out oral histories have been identified by professional historians and have raised important issues about the methodological limits of both qualitative approaches more generally and oral histories based on interviews specifically. Legman (cited in Perks et al., 1998: 80) suggests that interviews can be spurious at best with little preparation. While this can be augmented by improvements in techniques and the additions of documentary evidence, these methodological issues can raise serious concerns which are not easily rectified. Interviewees are often selected not because they represent a statistical norm but because they typify historical processes. This brings into question the interviewer's concept of historical processes and the relevance placed on the particular process 
being explored. In response, according to Perks, the real issues are historiographical, not statistical (Perks et al., 1998). The article now turns to describing a case study of an oral history undertaken with my mother and uses this to reflect on the issues and debates described above.

\section{A Case Study of an Oral History}

I considered a mutually exclusive epistemology would have been difficult in this research because in order for my mother to make sense of her life, she has to interpret it in relation to the social milieu and culture she experienced both as a child, but also within contemporary society. This research therefore draws on two research paradigms; constructionism and idealism. Constructionism suggests that we are all born into a world of meaning. We enter a social milieu in which a system of intelligibility prevails. We inherit a system of significant symbols. Merleau-Ponty (1962) suggests actual meaning emerges only when consciousness engages with them. Meanings are constructed by human beings as they engage with the world they are interpreting. Before there was consciousness on the earth capable of interpreting the world, the world held no meaning at all (Crotty, 1998). Crotty notes that:

When the mind becomes conscious of something, when it 'knows' something, it reaches out of, and into, that object ... Intentionality posits a quite intimate and very active relationship between the conscious subject and the object of the subject's consciousness (Crotty, 1998: 44).

Idealism, argues that our actions are not governed by cause and effect, but by the rules by which we use to interpret the world. People contemplate, interpret and act within their environments. Rules exist in social action through which we understand each other but are subject to different interpretations, for that reason we cannot predict human behaviour (Crotty, 1998).

Both these paradigms provide an assumption that we construct meaning for ourselves using an established system of symbols and rules and that human behaviour is not homogenous. These assumptions provide the ideal framework with which to explore individual's involvement in their own life. Their own perceptions and construction of their feelings and understanding can be interpreted using a phenomenological approach set within the two epistemological paradigms.

The research approach was purely qualitative in nature underpinned by phenomenological assumptions. The predominant aim of this research was to enable my mother's emotions and experiences to be captured. In order to achieve this, the interviews, rather than follow a set of pre-determined questions, took on the form of a series of conversations, which by their very nature, resulted in memories and events being recounted arbitrarily, with chronology being a secondary consideration. I had intended for the Second World War to be the point of origin of the interviews but as we shall explore later, this was not the case.

At the first interview the aims of the research were explained to my mother; that the study was for a dissertation and would explore aspects of her childhood up until and during the Second World War. It was made clear that my mother would have free rein to talk about any subject matter she chose in relation to her childhood and the Second World War. Informed consent and agreement to record the interview sessions was obtained. At the start of each subsequent interview, the purpose of the study was reiterated and any questions and concerns that my mother raised were discussed. Subsequent interviews began with a reiteration of the aims, a reflection of the last 
interview to recap and generate further discussion. The choice of interview venue was considered carefully to create a comfortable and safe environment; interviews were undertaken in my mother's home at suitable times chosen by her. Four two hour interviews were undertaken between November and December 2006.

A concept diagram was used to begin the first interview (Appendix One). A concept diagram is a graphical representation of thoughts and ideas as seen from the participant's perspective. The rationale for choosing a concept diagram was twofold: to test a different way of eliciting information, and to begin the interview process in a soft gentle way, in contrast to normal interview situations where the commencement of the interview is often rather formal and abrupt. The aim of utilising a concept diagram was to provide an instant image of my mother's first thoughts and also to help me in formulating further discussion prompts.

The interviews were recorded to allow me to focus on the conversation, and provide a rich text for analysis, rather than having to be distracted by taking inevitably limited notes. The purpose of recording the interviews was twofold, to give me a personal treasure; the actual voice of my mother, and also to prove a valuable archive; an essential evidence base to interrogate in depth on future occasions.

\section{Methodological Reflections}

I was keen to pursue Portelli's (1981) suggestion and capture my mother's perception of what she viewed as true (Portelli, 1981 cited in Roberts, 2002). In the case of this research, chronological order and precise accounts of events were not as significant as discovering the key events within the social and cultural background of my mothers childhood. As Thompson (2000) has argued, the ability to recall events which are most interesting to the participant provides valuable evidence in its own right.

The conversational approach worked well and generated a wealth of data. Although the interviews were difficult to begin with, once started the conversation flowed freely and without prompting. My mother appeared to forget that we were 'undertaking research' and settled into a steady and comfortable recounting of her experiences. Very often the interviews lasted up to two hours and in some instances they were hard to end. It was important to take this approach as the main tenet of the research was to enable my mother to tell her story, in her own words, viewed from her own perspective.

Although generating a rich and deep body of evidence, this example highlighted some challenges regarding the more practical processes of conducting oral history research. It was difficult to control interview length due to my mother's enthusiasm. The flexible nature of the research enabled my mother to express the things that she attached importance to. Often events were recounted in an unstructured and confused manner as one memory sparked off another relevant or acute memory within her. Data analysis therefore was very time consuming and complex, obliging no central point of focus.

I anticipated a tense start to the interviews, given the intimate nature of the subject matter. As described above, I used a concept diagram anticipating this method would provide an easy way of opening a conversational dialogue with my mother. I considered this to be a fundamental starting point with ideas generated spontaneously in visual form, and I thought it would provide a clear and straight forward way for my mother to express her thoughts. However; the concept diagram proved difficult to explain and did not work well. I found myself actually undertaking the task myself and leading to some degree my mother's thought processes. The idea of the diagram itself was hard for my mother to grasp and she was afraid she 'wasn't doing it right'. 
I had expected the concept diagram to reveal many more war time associations than it did. Only when prompted did my mother add rationing and bombing to the diagram, things we now associate with war time: rather she was more preoccupied with family members. This was not detrimental to the research overall but it did result in a change of emphasis and changed the opening dialogue to the exploration of her family and life before the war.

There are two key issues regarding debates about memory that emerged from the interviews: its unpredictability and its minutiae. My mother's ability to critically reflect and review her 'story' in the light of contemporary society added an unexpected dimension to the research. I was keen to explore my mother's life and wanted to follow closely Thompson's belief that she would remember things that interested her. I had anticipated that she would be able to articulate memories and events in chronological order and that these things would be remembered in a clear and concise way. In some cases my mother's memories had explicit connections as one memory triggered another. On other occasions, her memory was more erratic, describing different experiences from other times in her life. Once begun, the interviews flowed quickly, with events and experiences recounted one after another with little opportunity for further exploration. This raised an interesting dilemma: should the rhythm of the conversation be left to flow and gain as much information as possible or interrupt the flow of conversation to gain more detail? Judgements must be made about breadth or depth within the research. In this case, I chose breadth and allowed the flow of conversation to continue with a view to revisiting some topics should the opportunity arise. In the course of subsequent interviews there were indeed opportunities to revisit some of these issues further to increase depth.

Some of my mother's memories were very clear and recounted in depth with seemingly endless detail. Normal events involving family life and mundane tasks were told in a matter of fact way, just as if they had been experienced yesterday. For example, my mother's ability to describe the names of her teachers, their facial features and mannerisms and the power and fear they commanded was extraordinary. The importance of social networks and community members within her micro neighbourhood were also articulated in great detail. On the other hand, my mother's anxieties during the interviews were based on her inability to remember certain events. Her main concern was her struggle to remember her brother as a baby even though she could recount in great detail the events surrounding his actual birth. We returned to this issue in every interview, but she could not recall anything of his early life.

This research suggests that memory is not linked to interest alone, as Thompson (2000) suggests, but rather to key events and experiences. These played a prominent part in my mother's recollections. Added to this was her critical reflection of some of her experiences, illustrating the influence of the hermeneutic circle. ${ }^{2}$ Several times my mother was able to critically reflect and make comparisons between contemporary and past society highlighting differences in cultural norms and actual events in her life such as bullying, illness and childbirth.

Interviewing a close relative, with an intimate set of relationships, added a unique dimension to this research. This was a new experience and, grounding my thoughts within the literature, I was expecting the interviews I conducted with my mother to be different to those conducted with less familiar respondents. As an experienced researcher, who had conducted many interviews with challenging client groups and difficult topics, the interview process was similar but with some subtle nuances. These differences were not related to the mechanics of the interview itself, but rather with the very intrusive nature of the exploration. As Roberts (2002) suggests, in intimate relationships, the interviewer moves from an objective interviewer to an involved participant, in this case, asking very personal questions about sensitive topics. 
Thomson and Hobsbawm both argue that social bonds increase the danger towards social conformity and that there are no guarantees that increased intimacy will bring less inhibition (Thompson, 2000, Hobsbawm, 1997). Allied to this was my own presence; despite trying to remain objective, my own attitudes and beliefs were well known to my mother. How influential these were during the interview process remains unknown. These criticisms call into question the methodological limitations of intimate interview relationships and can perhaps question the validity of the data.

One possible weakness of oral histories revealed through this case study is Mason's (1996) suggestion that we are intimately engaging with a person's private life. I was acutely aware of this and it was very hard to remain 'objective' and treat my mother as an 'ordinary impartial' participant, I anticipated some difficulties with the interviews, mainly driven by my own anxieties about the personal and sensitive nature of the topic and our close mother/daughter relationship. I was anxious as to how to begin the interviews and expected my mother would find talking about her experiences intrusive, perhaps leading her to be reserved in her responses. I was also conscious about placing my mother in a compromised position; probing for information, perhaps intruding on sensitive issues my mother would prefer not to discuss. There was a constant awareness during the interviews of how I might probe for more detail and if in fact, given our relationship, it was appropriate to do so.

I had given little thought how to overcome these concerns and remain objective, except for using a topic guide for reference and a concept diagram as an ice breaker. But in fact, my worries were largely unfounded as the conversational approach worked well, and the homely surroundings created a relaxed atmosphere. There was no sense of awkwardness, no uncomfortable silences and my mother appeared willing to talk at length about her experiences. My mother told her 'story' in a detailed, if somewhat unpredictable way, in long swathes of oral testimony. She also reflected on cultural norms and the differences between current and past society which added a critical reflection to the research. In essence there was little need for deeper exploration, therefore mitigating to some degree the need to apply objectivity.

The main thrust of the literature suggests that an intimate interviewee interviewer relationship can undermine the reliability of oral histories. I would argue that this suggestion is spurious. I suggest that reliability can be preserved. Reliability equates to the replicability of the findings, but in qualitative research this is open to question. This can be mitigated by a strong methodology that can be replicated. Seale (1999) suggests:

good practice in relation to reliability and replication can be achieved through an aspect of reflexivity, that is , showing the audience of research studies as much as is possible of the procedures that have led to a particular set of conclusions (Seale, 1999: 158).

In summary, due to the strengths of the methodology, there were no real difficulties while undertaking the interviews. An element of trust was already explicit in our mother daughter relationship and I would argue that this facilitated an open and honest series of interviews. Although such trust need not always be present in intimate interviewee interviewer relations, this example suggests that the trust generated by the intimate relationship facilitated the success of these interviews. It was less clear however, to what extent the intimate family relationship impacting upon the power dynamics of the interviews.

I would argue that this research had a strong and transparent methodology underpinned by both constructionist and idealist paradigms, providing the ideal framework with which to explore my mother's involvement in her own life. In other 
words, the philosophy underpinning the research served to enhance the reliability of the data and the objectivity of the interviewer. My mother's own perceptions and construction of her feelings and understanding was interpreted using a phenomenological approach set within the two epistemological paradigms. This approach opened up the way to investigate a particular aspect of my mother's experience but more importantly the way she experienced it, expressed in her words. This was the main thrust of the research and the enabling of 'the telling' in her words reinforced the reliability of the research. It was never the intention to draw generalisations from this research. I acknowledge the arguments that suggest biographical research techniques have their limitations, but this example does not suggest them to be problematic. Based on my experience, I would therefore question Thompson's (2000) assertions that close social bonds can increase social conformity.

\section{Conclusion}

In recent years oral histories have made a positive contribution to research, carving out their own research paradigm and by the end of the 20th century this approach has become a respected and accepted technique for social research. The principal ideology of oral histories is capturing the lived experience from a participant perspective, in essence, opening up new avenues of exploration. The previous homogeneous appetite for written evidence has been challenged by oral histories and, as society has changed, oral histories have evolved to enable those from previously excluded populations to tell their stories.

Unreliability of memory forms the central critique of oral histories, based upon the propensity for participants to exaggerate, misremember and to recall past events with any certainty is questioned. The lived experience is said to be tainted by the influential effects of culture and other societal influences over time, thus making memory more opaque. Whilst these factors were present in the case study discussed in this article, they did not prevent important data being gathered which, though specific, retains its value in capturing perceptions and insights into historical events and life experiences.

The open and unstructured conversational approach, coupled with familiar interview surroundings, created a relaxed environment and generated a plethora of data. However, drawing on this experience there does not appear to be any clear evidence that intimate interview relationships are significantly different to more formal interview situations. I question Hobsbawn's theory (1997) which suggests that increased intimacy brings less inhibition to the interview. The breadth and depth of the data collected in this case certainly undermines this theory. However, there will always be an unknown element, as in all forms of research, regarding the conscious or subconscious decisions taken by my mother during the interview process and how this has affected the data.

I suggest that the quality of data obtained from oral histories depends on the chosen methodology. I concur with Perks (1998), who suggests interview techniques, and more importantly, the strength and capabilities of the interviewer, can play an influential role in data collection. I would argue, in this case, chronological order and precise accounts of events were not as salient as discovering the key events within the social and cultural background of my mother's childhood. As Thompson (2000) has argued, the ability to recall events which are most interesting to the participant provides valuable evidence and this was certainly the case in this instance. Coupled with this, key events featured prominently within my mothers recollections.

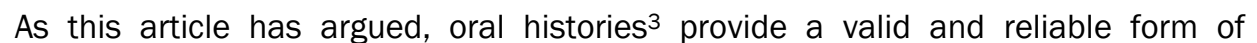
research, particularly giving voice to those groups previously ignored by traditional 
historians. There is a strong case for the inclusion of oral histories in social research where they can add both breadth and depth increasing our understanding of the lived experience.

\section{Notes}

1 Marwick (1970) suggests an acceptable hierarchy of sources: contemporary letters, informer's reports, depositions, press and parliamentary reports social enquiries, diaries and autobiographies.

2 Erban suggests that biographical methods connect with the notion of the hermeneutic circle. He advocates a bridge between hermeneutics where the emphasis is on the exegetical interpretation of the data and phenomenology, where the emphasis is on the establishment of subject's meanings by indicating a mix of types of hermeneutics and the sociological phenomenology or verstehen method. He argues that this will help to broaden phenomenological approaches and allay some of the assumptions that individuals have a complete understanding of their perspectives operating in their ordinary actions (Roberts, 2002).

3 A similar approach to oral histories has been used by researchers at the Centre for Regional economic and Social Research at Sheffield Hallam University to explore homelessness histories. Using a 'homeless journey model' (Reeve et al., 2007) participants are encouraged to talk about their homelessness in the form of a conversation much the same as the traditional oral history approach. This has been particularly useful where participants have been of a challenging nature such as drug users, alcohol users, and sex workers for example.

\section{Acknowledgements}

I would like to thank my mother for giving me the opportunity to explore her life and John Flint for his valuable input and constant encouragement.

* Correspondence Address: Elaine Batty, Centre for Regional Economic and Social Research, Sheffield Hallam University, Unit 10, Science Park, Howard Street, Sheffield, S1 1WB. Email: e.batty@shu.ac.uk.

\section{References}

Bryman, A. (2004) Social Research Methods. Oxford: Oxford University Press. Crotty, M. (2003) The Foundations of Social Research. London: Sage.

Denzine, N.K. and Lincoln, Y.S. (2000) Handbook of Qualitative Research. London: Sage.

Hatch, J.A. and Wisniewski, R. (Eds) (1995) Life History and Narrative. London: The Falmer Press.

Hobsbawn, E. (1997) On History. London: Weidenfeld and Nicholson.

Marwick, A. (1970) The Nature of History. London: Macmillan.

Mason, J. (1996) Qualitative Researching. London: Sage.

Nevins, A. (1996) Oral History: how and why it was born, In: D.K. Dunaway and W.K. Baum (eds) Oral History: An Interdisciplinary Anthology, $2^{\text {nd }}$ edn. Walnut Creek, CA: AltaMira Press. 
p. 120. Reflections on the Use of Oral History Techniques in Social Research

Perks, R. and Thompson, A. (1998) The Oral History Reader. London: Routledge.

Reeve, K. with Goudie, R. and Casey, R. (2007) Homeless Women: Homelessness Careers, Homelessness Landscapes. London: Crisis.

Richie, J. and Lewis, J. (Eds) (2003) Qualitative Research Practice. London: Sage Publications.

Roberts, B. (2002) Biographical Research. Buckingham: Open University Press.

Seale, C. (1999) The quality of qualitative research. London: Sage.

Summerfield, P. (1984) Women workers in the Second World War. London: Croom Helm.

Summerfield, P. (2004) Culture and Composure: Creating Narratives of the Gendered Self in Oral History Interviews. Cultural and Social History, 1, 65-93.

Thompson, P. (2000) The Voice of the past Oral History. Oxford: Oxford University Press. 
p. 121. Reflections on the Use of Oral History Techniques in Social Research

\section{Appendix One: Concept Diagram}

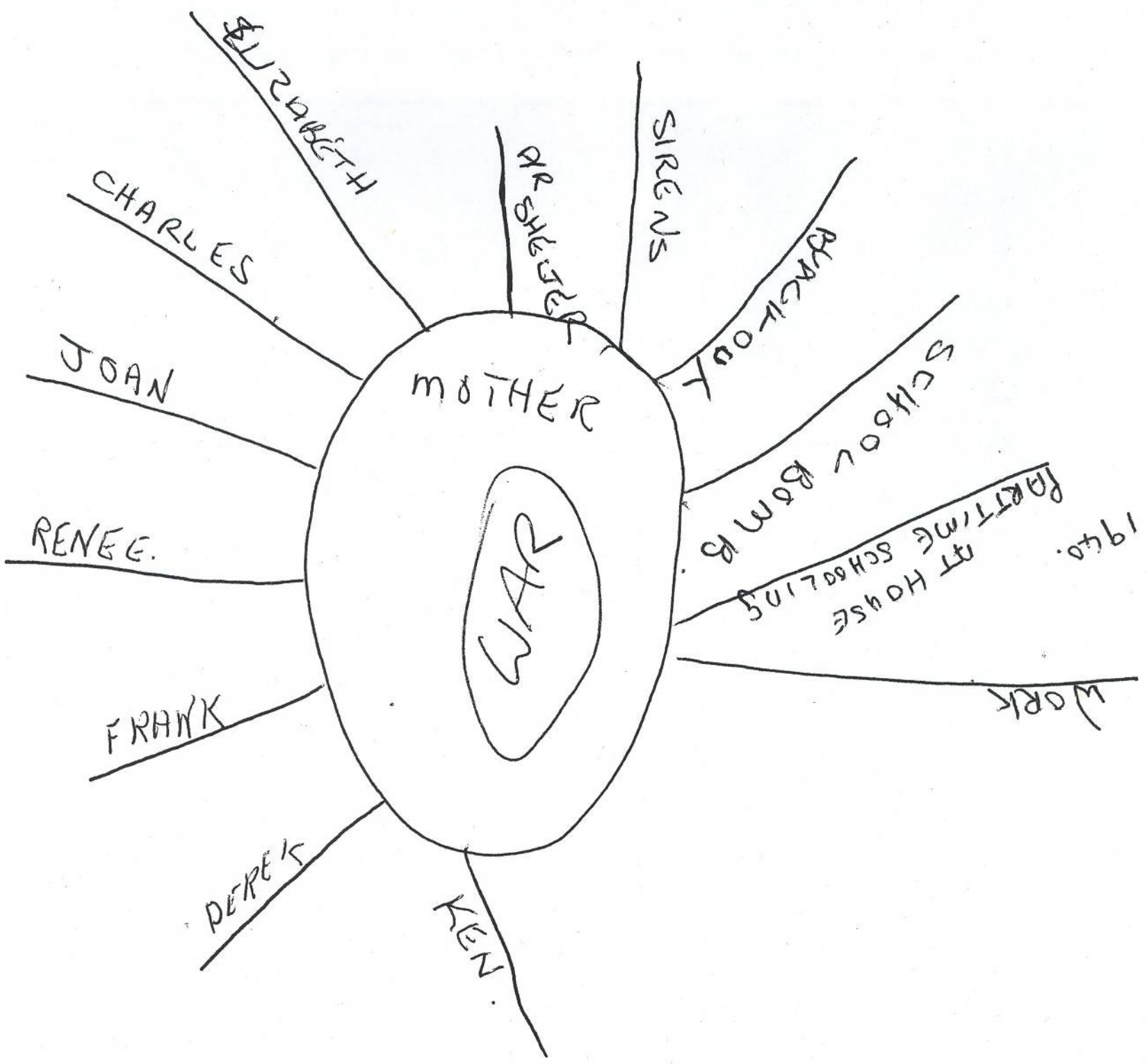

